\title{
WHY DO FEWER WOMEN THAN MEN APPLY FOR GRANTS AFTER THEIR PHDS?
}

\author{
Lynne Goldstein, Barbara J. Mills, Sarah Herr, Jo Ellen Burkholder, Leslie Aiello, \\ and Christopher Thornton
}

In spring 2013, the Society for American Archaeology created the Task Force on Gender Disparities in Archaeological Grant Submissions because of an apparent disparity in the rates of senior (post-PhD) proposal submissions by men and women to archaeology programs at the National Science Foundation (NSF) and the Wenner-Gren Foundation for Anthropological Research. Although NSF success rates for men and women between 2009 and 2013 were roughly equal, the number of senior women archaeology submissions was half that of men. Given the documented increase in the proportion of women in academic archaeology, this representation of women seemed low. Moreover, submissions for NSF doctoral dissertation improvement grants were evenly divided between men and women. Statistics for Wenner-Gren noted the same general disparity in archaeology. This study examines and integrates a variety of data sources, including interviews with post-PhD women, to determine whether or not there is a problem in research grant submissions. Although the results indicate that there is a problem, it is multifaceted. Women are not well represented at research-intensive universities, and some women instead practice what we term "scaffolding" to integrate smaller pots of money to accomplish their research. Recommendations are provided for female applicants, academic departments, the Society for American Archaeology, and granting agencies.

En la primavera de 2013 la Society for American Archaeology (SAA) creó el Equipo Especial de Disparidades de Género en las Presentaciones de Becas Arqueológicas debido a la aparente disparidad entre hombres y mujeres en las tasas de presentaciones de propuestas de alto nivel (posdoctorado) a programas de arqueología en la National Science Foundation (NSF) y la Wenner-Gren Foundation for Anthropological Research. Aunque las tasas de éxito de la NSF para hombres y mujeres de 2009 a 2013 fueron aproximadamente iguales, la cantidad de presentaciones de alto nivel sometidas por mujeres fue la mitad que por hombres. Dado el aumento documentado en la proporción de mujeres en la arqueología académica, esta representación de mujeres parecía baja. Además, las presentaciones para las becas de mejora de disertaciones doctorales de la NSF se dividieron equitativamente entre hombres y mujeres. Las estadísticas de la Wenner-Gren notaron la misma disparidad general en arqueología. Este estudio examina e integra una variedad de fuentes de datos, incluyendo entrevistas con mujeres de nivel posdoctoral, para determinar si hay un problema en las presentaciones para becas de investigación. Aunque los resultados indican la existencia de un problema, este es polifacético. Las mujeres no están bien representadas en las universidades de investigación intensiva, y algunas mujeres practican lo que llamamos "andamiaje”, integrando pequeñas sumas de dinero para llevar a cabo su investigación. Se ofrecen recomendaciones para candidatas, departamentos académicos, la SAA y agencias otorgantes.

Lynne Goldstein $\square$ Department of Anthropology, Michigan State University, 655 Auditorium Drive, East Lansing, MI 48824, USA (lynneg@msu.edu, corresponding author)

Barbara J. Mills - School of Anthropology, P.O. Box 210030, University of Arizona, Tucson, AZ 85721, USA

(bmills@email.arizona.edu)

Sarah Herr $\square$ President, Desert Archaeology, Inc., 3975 North Tucson Boulevard, Tucson, AZ 85716, USA

Jo Ellen Burkholder $\square$ Department of Women's and Gender Studies, University of Wisconsin-Whitewater, 800 West Main Street, Whitewater, WI 53190, USA

Leslie Aiello President-Emerita, Wenner-Gren Foundation for Anthropological Research, 470 Park Avenue South, New York, NY 10016, USA

Christopher Thornton $\square$ Senior Director, Grants and Human Journey, National Geographic Society, 1145 17th Street NW, Washington, DC 20036, USA

American Antiquity 83(3), 2018, pp. 367-386

Copyright (C 2018 by the Society for American Archaeology

doi:10.1017/aaq.2017.73 
$\mathrm{P}$ ast research on gender disparities in archaeology as a profession has investigated hiring (Beaudry 1994; Chester et al. 1994; Hutson 1998; Stark et al. 1997; Zeder 1997), ${ }^{1}$ publishing (Bardolph 2014; Bardolph and VanDerwarker 2016; Beaudry and White 1994; Hutson 2002; Rautman 2012; Stark et al. 1997; Victor and Beaudry 1992), research grant submissions and success rates (Yellen 1983, 1991), representation at professional meetings (Bardolph and VanDerwarker 2016; Burkholder 2006; Claassen et al. 1999), and other important issues (see Nelson, Nelson, and Wylie 1994). These studies are part of a larger literature on gender disparities in science (e.g., Ceci and Williams 2011; Clauset, Arbesman, and Larremore 2014; Finkel and Olswang 1996; Fox and Colatrella 2006; Larivière et al. 2013; West et al. 2013; Wolverton, Nagaoka, and Wolverton 2014). Our research builds on this work by looking specifically at sex differences in post- $\mathrm{PhD}$ research grant submission rates.

The research we discuss here was initiated as part of the Society for American Archaeology (SAA) Task Force on Gender Disparities in Archaeological Grant Submissions. SAA created the task force to investigate the disparity in the rates of senior (post-PhD) proposal submissions by male and female principal investigators (PIs) to archaeology programs at both the National Science Foundation (NSF) and the WennerGren Foundation for Anthropological Research (WG). For example, from 2009 to 2011 at NSF, the number of submissions from women was half that from men: 270 women versus 542 men. Yet the success rates of men and women over the same period were roughly equal (35\% for women vs. $33 \%$ for men). Moreover, submissions for doctoral dissertation improvement grants at NSF-a significant pipeline to future senior grant submissions-were more evenly divided between men and women. Statistics for NSF showed no difference in rates of submission by men and women in other anthropological subdisciplines. Those from WG did show that postdoctoral submissions by women were low in both biological anthropology and archaeology. Since the task force was created, women's submissions to WG have somewhat rebounded, but NSF rates remain low.
Given an increase in the proportion of women in academic archaeology among early- and midcareer academics (Hutson 2002), this 33\% representation of women in the applicant pool seemed low to NSF's program officer in archaeology, John Yellen, and members of an Archaeology Program independent review team, Leslie Aiello (WG) and Melinda Zeder (Smithsonian Institution). Following their appointment as cochairs of the SAA task force, Lynne Goldstein and Barbara Mills received an NSF Early-Concept Grant for Exploratory Research (BCS-1449667) to conduct research on why submissions to NSF by senior women were consistently low. Two other SAA members, Jo Burkholder and Sarah Herr, joined the task force and assisted in the research.

The primary question we asked was: Why do post-PhD female archaeologists not apply for extramural research funding as often as males? Based on our presentations at two SAA forum settings and numerous communications with colleagues, we developed multiple working hypotheses to address this question. This article summarizes our research; the full report is available from the task force's website (http: //saa-gender.anthropology.msu.edu).

\section{Data Collection and Sources}

This project used multiple sources of information, including (1) demographic data from the American Anthropological Association's $A A A$ Guide to Departments of Anthropology of 2011; (2) demographic data from member surveys conducted by SAA in 2003 and 2010; (3) detailed data from publicly available records of funded proposals from the NSF and National Endowment for the Humanities (NEH); (4) data on funded and unfunded proposals collected for us by WG and the National Geographic Society (NGS), as well as several years' data on NSF submissions; and (5) interviews with 36 post$\mathrm{PhD}$ women in academic archaeology to determine their strategies for funding archaeological research, as well as the kinds of research they undertake. Task force members conducted all interviews using an agreed-upon set of questions as a beginning; interviews averaged 40-60 minutes and were primarily conducted by phone (a 
few were conducted in person at conferences at the interviewee's request). The sample was balanced by geographic region and academic rank and was drawn from a larger list composed of (a) those who e-mailed the task force cochairs before the 2015 SAA meetings indicating their willingness to assist, (b) those who attended the SAA 2014 forum and indicated on the signin sheet that they were willing to be interviewed (approximately 100 individuals attended the forum), and (c) women who received doctoral dissertation improvement grants between 1990 and 2009. We included this last group because, since its members had been successful in receiving NSF grants as graduate students, they might therefore be more likely to apply for a subsequent grant. We stopped at 2009 since that seemed to be the minimum amount of time for people to complete their degrees, be hired in a position, and apply for new grants. Although we interviewed 36 women, we originally selected a sample of 70 women to interview; 34 women either were not available, were out of the country, or did not respond to our e-mails and calls. ${ }^{2}$

\section{Agency and Foundation Data on Grants}

This section focuses on data collected and analyzed for the NSF (provided anonymously), the WG (provided by Dr. Leslie Aiello, presidentemerita, Wenner-Gren), and the NGS (provided by Dr. Christopher Thornton, lead program officer of research, conservation, and exploration). In each case, collected internal data allow a consideration of trends in all submitted applications. Due to privacy laws, it was not possible for the task force to gain direct access to all submitted proposals-agencies and foundations can only publicly share detailed data on successful proposals. The WG data enable comparisons across all anthropological subdisciplines. Since all NGS projects must be field-based, data from this granting program provide a control on field versus laboratory project proposals for comparison with NSF.

\section{NSF Applicants and Trends}

NSF provided three fiscal years (FYs) of proposal data: FY2004, FY2008, and FY2013. For any given year, the official NSF number may vary due
Table 1. Division of National Science Foundation Archaeology Applicants by Sex.

\begin{tabular}{lccr}
\hline $\begin{array}{l}\text { Doctoral Dissertation } \\
\text { Proposals by Fiscal } \\
\text { Year (FY) }\end{array}$ & $\begin{array}{c}\text { Count (\%) } \\
\text { Male }\end{array}$ & $\begin{array}{c}\text { Count (\%) } \\
\text { Female }\end{array}$ & $n$ \\
\hline All Proposals & & & \\
FY2004 & $37(62)$ & $23(38)$ & 60 \\
FY2008 & $35(48)$ & $38(52)$ & 73 \\
FY2013 & $51(46)$ & $59(54)$ & 110 \\
Archaeometry Proposals & & & \\
FY2004 & $11(85)$ & $2(15)$ & 13 \\
FY2008 & $12(80)$ & $3(20)$ & 15 \\
FY2013 & $12(60)$ & $8(40)$ & 20 \\
"Senior” Archaeology Proposals & & \\
FY2004 & $78(70)$ & $33(30)$ & 111 \\
FY2008 & $63(63)$ & $37(37)$ & 100 \\
FY2013 & $64(65)$ & $34(35)$ & 98 \\
\hline
\end{tabular}

to the date officially recorded for that proposal and other factors. Table 1 shows the division by sex across different grant competition categories. Dissertation proposals are more evenly split between males and females, with slightly more female proposal submissions. This reflects the fact that more females than males earned $\mathrm{PhD}$ degrees in archaeology in the last decade. However, at the senior level, twice as many males submitted proposals as females. (Archaeometry proposals are especially out of balance, but the number of these proposals is so small that the percentages may not be meaningful.) The success rates, however, are roughly equal; in 2013, for example, $22 \%$ of male-submitted proposals versus $26 \%$ of female-submitted ones were successful.

One question is whether there is a difference in the sex of the students' advisers. For NSF, the difference is significant $(p=0.0087)$, but the large number of male advisers skews this distribution. A total of $76 \%$ of advisers were male, and $24 \%$ were female. Of the students applying, $54 \%$ were female, and $46 \%$ were male. Only $14 \%$ of men had female advisers, and $64 \%$ of women had male advisers. That said, $75 \%$ of female advisers were advisers to women.

There was no significant difference in the dollar amounts requested between male and female graduate students or between male and female senior researchers; success was based on merit, not cost. In both male and female proposals, 
Table 2. Number and Percentage of Wenner-Gren Applications and Success Rates by Subdiscipline for 2015 and 2001-2015 Combined.

\begin{tabular}{|c|c|c|c|c|c|c|}
\hline \multirow[b]{2}{*}{ Grant Subdiscipline } & \multicolumn{3}{|c|}{2015} & \multicolumn{3}{|c|}{$2001-2015$} \\
\hline & $n$ & $\%$ & $\begin{array}{c}\text { Succes } \\
\text { Rate }(\%)\end{array}$ & $n$ & $\%$ & $\begin{array}{c}\text { Success } \\
\text { Rate }(\%)\end{array}$ \\
\hline \multicolumn{7}{|c|}{ Dissertation Fieldwork Grant } \\
\hline Archaeology & 146 & 15.0 & 15.8 & 1,656 & 14.1 & 14.4 \\
\hline Linguistics & 25 & 2.6 & 8.0 & 394 & 3.4 & 19.8 \\
\hline Physical-biological & 131 & 13.5 & 13.7 & 1,487 & 12.7 & 16.7 \\
\hline Social-cultural & 669 & 68.9 & 15.4 & 8,190 & 69.8 & 14.5 \\
\hline Total & 971 & 100.0 & 15.0 & 11,727 & 100.0 & 14.9 \\
\hline \multicolumn{7}{|c|}{ Post-Ph.D. Research Grant } \\
\hline Archaeology & 63 & 22.4 & 22.2 & 1,011 & 27.5 & 19.4 \\
\hline Linguistics & 4 & 1.4 & 25.0 & 109 & 3.0 & 16.5 \\
\hline Physical-biological & 67 & 23.8 & 20.9 & 730 & 19.9 & 19.6 \\
\hline Social-cultural & 147 & 52.3 & 13.6 & 1,825 & 49.7 & 12.1 \\
\hline Total & 281 & 100.0 & 17.4 & 3,675 & 100.0 & 15.7 \\
\hline Grand Total & 1,252 & & 15.6 & 15,402 & & 15.1 \\
\hline
\end{tabular}

about $74 \%$ of proposals were for fieldwork as opposed to laboratory work. Nor is there a significant difference in the age of applicants. The "post-PhD age" of all senior applicants and of successful senior applicants is the number of years after completion of the $\mathrm{PhD}$. For all applicants, the average ages were 15.5 years (males) and 12.7 years (females). For successful senior applicants, they were 15.7 years (males) and 12.8 years (females).

\section{Wenner-Gren Applicants and Trends}

WG provides research funds for both doctoral students (Dissertation Fieldwork Grant) and senior anthropologists (Post-Ph.D. Research Grant). Both programs have a grant maximum of $\$ 20,000$. The most recent available statistics are from 2015. WG received 971 applications from doctoral students and 281 applications from senior anthropologists (total $=1,252$ ) and funded 146 doctoral applications ( success rate $=15.0 \%$; amount expended $=\$ 2,357,729)$ and 49 senior applications (success rate $=17.5 \%$; amount expended $=\$ 835,922)$.

The percentages of applications received across the subdisciplines in 2015 are consistent with the summed 15-year percentages, 20012015 (Table 2). The success rates are also consistent. In comparison with the subdisciplinary percentages for the Dissertation Field- work Grant, WG received proportionately more senior applications from archaeologists and biological anthropologists than from social anthropologists. In pure numbers, however, social anthropology applicants dominated both doctoral and senior submissions.

With one exception, WG received more applications from women than from men across the subdisciplines and the two funding programs, and applications from women show a steady increase in numbers (Figure 1a, c-f). The exception is the archaeology Post-Ph.D. Research Grant, where only $36.0 \%$ of the submissions were from women in 2015 (39.8\% over the 15 years, 2001-2015), and there was no increase in applications over the past 15 years (Figure 1b). In the other subdisciplines (for both doctoral and senior funding), up to $72.3 \%$ of the applications were from women over the 15-year period.

The ratio of senior to doctoral submissions provides a rough indication of the involvement of women and men in research once the doctorate is received. In both archaeology and biological anthropology, the number of applications from senior men in 2015 (and over the 15year period) was approximately $71 \%-82 \%$ of the number received from male doctoral students. For women, the proportion is much lower, 26\%$44 \%$. In social anthropology, the proportion for both men and women is lower but roughly 

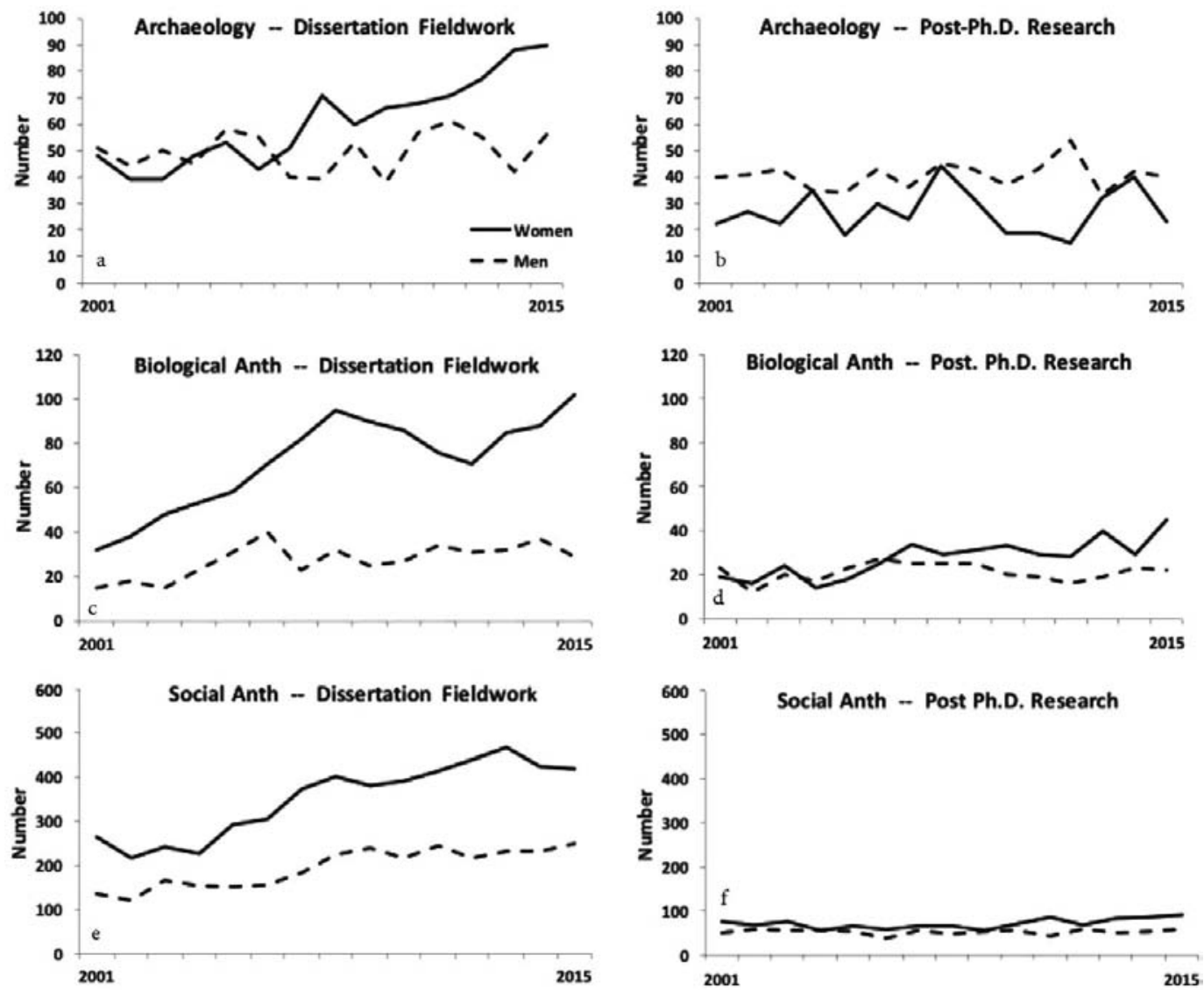

Figure 1. Number of Wenner-Gren submissions by sex, subdiscipline, and grant program for dissertation fieldwork $(a, c, e)$ and post-PhD research $(b, d, f)$ from 2001 to 2015. Anth = anthropology.

equal (men $\approx 22 \%-26 \%$; women $\approx 20 \%-22 \%$ ). Whatever is influencing the decision of senior social anthropologists to apply for WG funding affects men and women similarly. However, in both archaeology and biological anthropology, senior women apply at a much lower rate than do men in relation to the number of submissions received from doctoral students.

Archaeology is the only subdiscipline where there are consistently more applications from senior men than women (Figure 1b). Although there is a similarly high proportion of senior grant applications from men in archaeology and biological anthropology, archaeology differs in having a higher proportion of submissions from male doctoral students (Figure 1a).

In brief, the WG data do not point to grant issues that affect only senior women in archaeology. There is a considerable reduction in sub- missions from senior women in relation to the number expected on the basis of applications from doctoral students across the subdisciplines. This drop is greater in social anthropology than in other disciplines but appears to affect men and women similarly. In biological anthropology and, especially, archaeology, proportionately fewer senior women apply for grants.

\section{National Geographic Society Applicants and Trends}

NGS provides small $(<\$ 25,000)$ single-year grants to anyone working anywhere in any fieldbased research discipline. Thus, archaeology applications are judged relative to similarly sized requests for funding in other science fields (e.g., botany or paleontology), rather than against only other anthropology or archaeology proposals. From January 2005 to December 2014, 


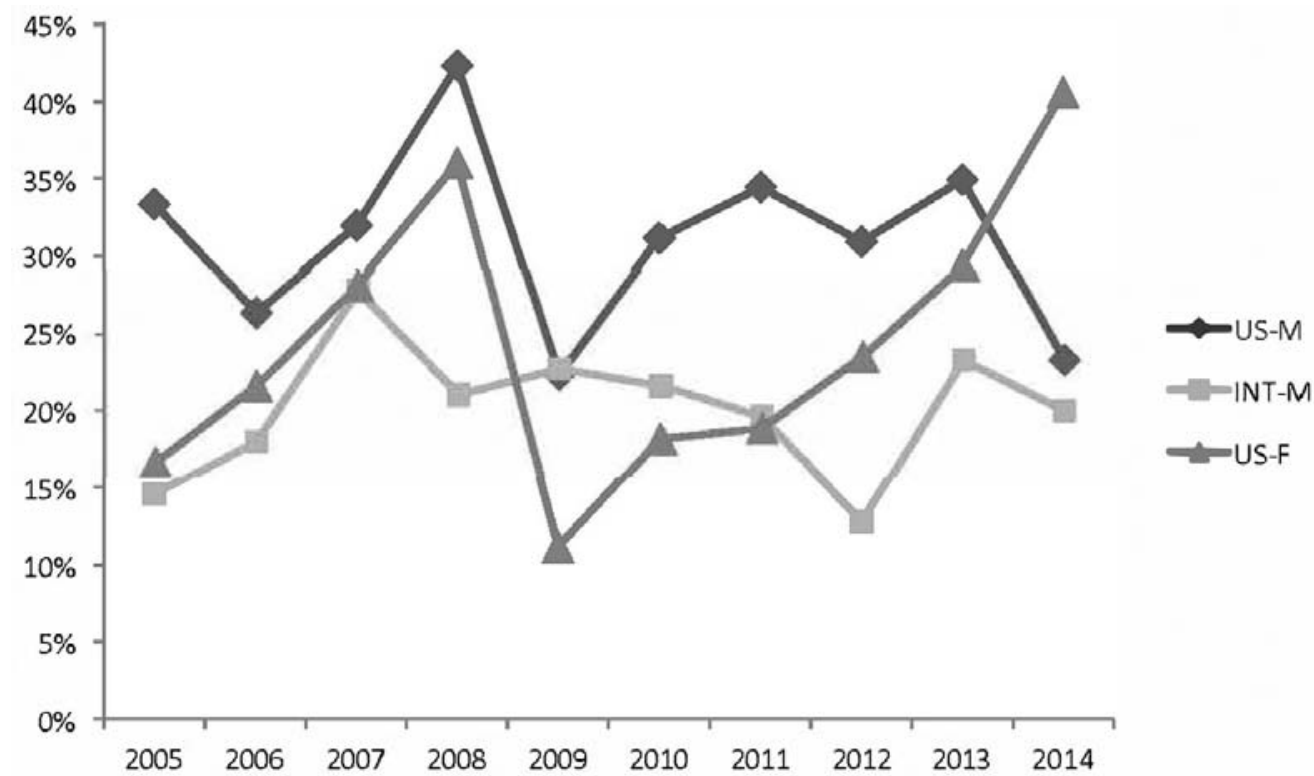

Figure 2. Number of grant applicants for National Geographic Society (NGS) grants from 2005 to 2014. US-M = USbased men; INT-M = non-US-based men; US-F = US-based women; the number of non-US-based women was too small to include.

NGS received 1,611 applications for archaeology; $58 \%$ were from US residents (Figure 2). Although NGS has multiple programs that provide archaeology grants, this study used only Committee for Research and Exploration and Global Exploration Fund applications, as these are the only two programs that require a $\mathrm{PhD}$ to apply, making them more comparable to NSF's senior grants.

Of the 1,611 archaeology applicants, 495 $(31 \%)$ were female, with women making up $31 \%$ of US-based applicants and $30 \%$ of nonUS-based applicants. Although the number of applications to NGS dropped considerably in the 2009-2010 period (post-economic crisis), the number of US-based female applicants rebounded quickly in 2011, while the number of international applicants (both male and female) began to steadily increase after the crisis due to active recruitment activities by NGS (including the creation of the Global Exploration Fund program in 2011). Interestingly, the number of US-based male applications has never returned to the levels seen before and during the economic crisis of 2008-2009.

The overall success rate for archaeology applicants to NGS was $25 \%$ - and slightly higher (29\%) for US-based applicants (Figure 2). The success rate for US-based women saw two periods of growth-a positive trend between 2005 and 2008 (from $15 \%$ to $35 \%$ ) and then another from 2009 to 2014 (from 10\% to 40\%). The earlier positive trend was at least partially due to the decline of applications from US-based women between 2006 and 2009, but the recent positive trend may have been the result of active recruitment of female applicants by NGS or positive bias by the grant committees. In contrast, the success rate for US-based men remained relatively constant, $\sim 25 \%-35 \%$ over the 10 -year period. Non-US-based men and women had the same average success rate of about $20 \%$, despite an increase in the number of applications from non-US residents (a trend offset by increasing the amount of funding restricted to international applicants through the Global Exploration Fund program).

Of all US-based applicants in archaeology, $80 \%$ applied to work abroad (compared with $90 \%$ in anthropology and 65\% in geology/ paleontology). And $84 \%$ of US-based female applicants in archaeology applied to work abroad (range: $71 \%-96 \%$ of female applicants/year).

Between 2005 and 2014, the number of female archaeologists applying for grants lagged behind the number of male archaeologists, but 


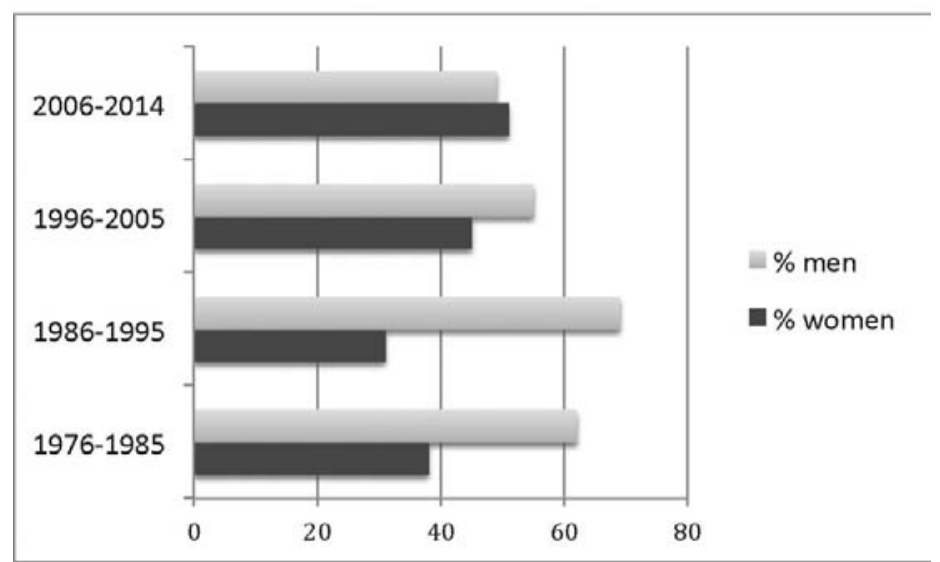

Figure 3. National Endowment for the Humanities (NEH) grants of all types awarded to archaeologists by decade and sex.

women's application rate was apparently less affected by the 2008-2009 economic crisis. Indeed, US-based female applicants currently enjoy a higher success rate than their male peers, while international female applicants are on par with their male colleagues (suggesting that language and culture, rather than gender, play significant roles in the ability to get grants from NGS).

\section{National Endowment for the Humanities Trends}

Although we lack detailed data on NEH applicants, we did access $2016 \mathrm{NEH}$ data on grants awarded. These data represent all NEH programs, including faculty fellowships, conferences, and research grants (Figure 3). Based on all grant categories, women have achieved parity in NEH grants over the last decade, but because fellowships are included, these data are not necessarily comparable to other kinds of grants.

\section{Research Questions and Common Assumptions about Grant Submissions}

Our research investigated the following questions and ideas, drawing upon the multiple data sources compiled for the project. In our interview sample, $78 \%$ of the 36 women interviewed had applied for senior NSF grants, and $70 \%$ were eventually successful. These high numbers are driven by the fact that the interview sample focused on women who had received NSF dissertation grants, since these should be the individuals most likely to apply for senior grants. A subset of $13 \%$ had received NSF dissertation grants but did not apply for senior grants. Reasons for not applying included living in Canada (and thus ineligible), being in non-tenure-track positions, and working in cultural resource management (CRM).

Our focus on academic women is based on the fact that the great majority of grant proposals to NSF, WG, and NGS come from academia. Since the primary task was to examine why more senior women were not applying for grants, we focused on the pool of researchers who would normally be expected to apply.

In terms of their professional positions, six of the women interviewed were assistant professors, 10 were associate professors, 10 were full professors, and two were emerita professors. Three were in nontenured university positions, two worked for government, one worked for a CRM firm, and two others were independent researchers working on soft money (but not NSF funds).

\section{Disparities in research grant submissions are proportional to the number of male versus female archaeologists and especially to the number in job settings where grant writing is encouraged.}

The first proposition is supported by data provided by the American Anthropological Association (AAA). ${ }^{3}$ Although women are granted 
Table 3. Proportion of Women versus Men Represented in the American Anthropological Association's Data Between 2008 and 2011.

\begin{tabular}{lcccc}
\hline Sex & 2008 & 2009 & 2010 & 2011 \\
\hline Female & $4,679(44.0 \%)$ & $4,737(44.5 \%)$ & $4,754(44.7 \%)$ & $4,833(45.0 \%)$ \\
Male & $5,870(55.2 \%)$ & $5,825(54.7 \%)$ & $5,793(54.5 \%)$ & $5,787(54.0 \%)$ \\
Unknown & $82(0.8 \%)$ & $90(0.8 \%)$ & $80(0.8 \%)$ & $90(1.0 \%)$ \\
Total & 10,361 & 10,652 & 10,627 & 10,710 \\
\hline
\end{tabular}

more than half of all $\mathrm{PhD}$ degrees today, they are not similarly represented in professional positions (Speakman et al. 2017). Within academia, women are more likely to be found in institutions that grant only bachelor's degrees; they are less likely to be found in $\mathrm{PhD}$-granting institutions. The situation has not improved as much as might be expected given the increasing proportion of women earning their doctorates. Our interviewees in all academic positions underscored that grants were very important for promotion and tenure decisions. Once in these positions women should be applying for external support, but the numbers of women in academia are not keeping up with $\mathrm{PhD}$ production.

There are limitations and biases in the data used to examine the overall demography of the archaeological discipline. Individuals in the $A A A$ Guide constitute the most likely population to apply for grants, but it ignores all those women with doctorates who are not in academic jobs or whose institutions chose not to list themselves in the $A A A$ Guide, which is a relatively small number, as well as many trailing spouses, where one individual has a tenure-stream job and the other spouse has secured an adjunct or less secure position. In addition, some nonprofit and many CRM firms are not in the Guide, and museums (especially smaller ones) are not consistently listed.

Over the four years of AAA data to which we had access, the proportion of males to females in anthropology remained remarkably similar (Table 3). Because of this similarity and the time it took to clean the data, we focused on the 2011 AAA data, which identifies 2,447 individuals as archaeologists. Of these, 1,566 (64\%) are men, and $868(36 \%)$ are women; 13 individuals $(<1 \%)$ are unknown. Archaeologists are represented in several different kinds of professional positions, and in most, there is a $60 / 40$ split, with $60 \%$ of positions occupied by men and $40 \%$ occupied by women across different professional job types. Figure 4 shows that women now make up slightly more than half of those receiving doctorates in archaeology, but Figure 5 shows that these changing demographic proportions have not translated into job proportions. Fewer women are entering museums and academic positions in departments with graduate programs, that is, positions requiring, and supporting, research as a condition of employment.

We used the 2011 AAA data to focus on academic positions for archaeologists. Figure 6 shows the distribution, by sex, of the kinds of academic institutions in which people work. The trend noted above is replicated here: females are underrepresented in academia, and there are fewer women in positions at institutions where research is a significant requirement of the position. Partitioning the data in terms of public or private institutions, women constitute $35 \%$ of all academic positions in each category, while men represent $65 \%$ in each.

It is likely that the demographic data summarized above reflect a significant reason why fewer senior women apply for NSF grants-there are twice as many men in $\mathrm{PhD}$-granting research institutions. Faculty members in PhD-granting institutions teach fewer courses, have graduate students to assist them, and maintain a stronger peer/mentor network.

\section{Women in archaeology have heavier service burdens and hidden labor, reducing time available to work on major grant proposals.}

Our interviews indicate that women have heavy service burdens and are stretched very thin, but we do not have the data to indicate that their burden is heavier than males' or that female archaeologists have heavier burdens than researchers in other anthropology subdisciplines. 


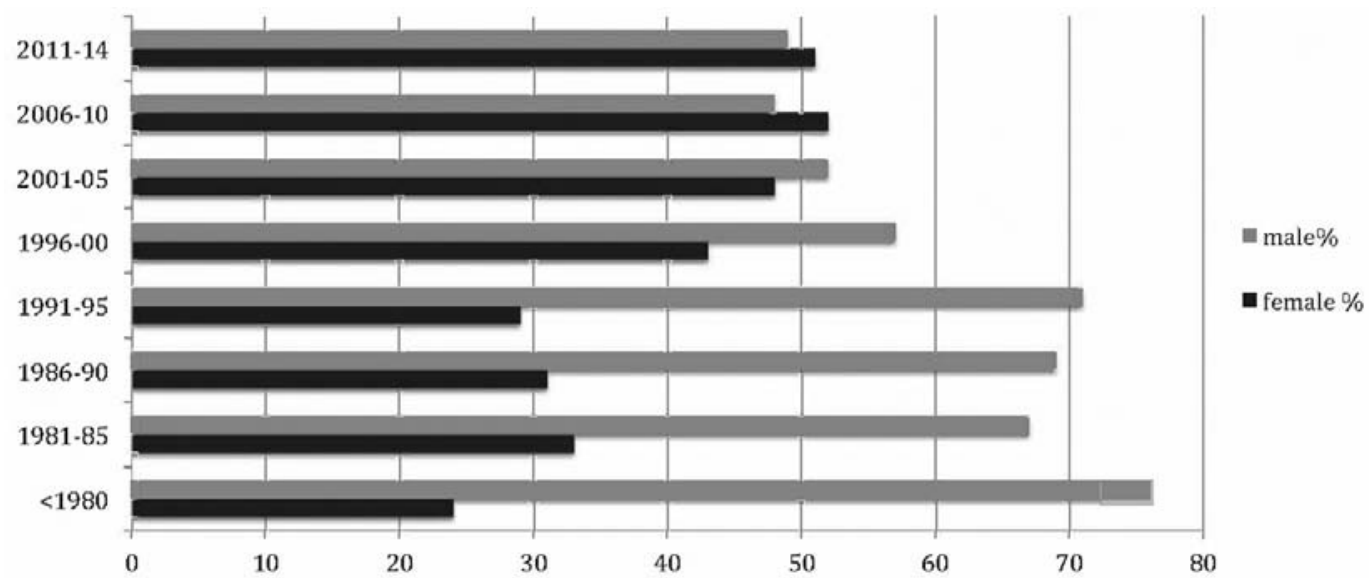

Figure 4. Ordered by five-year intervals, percentages of female and male archaeologists who received their degrees over time (based on 2011 data provided by the American Anthropological Association).
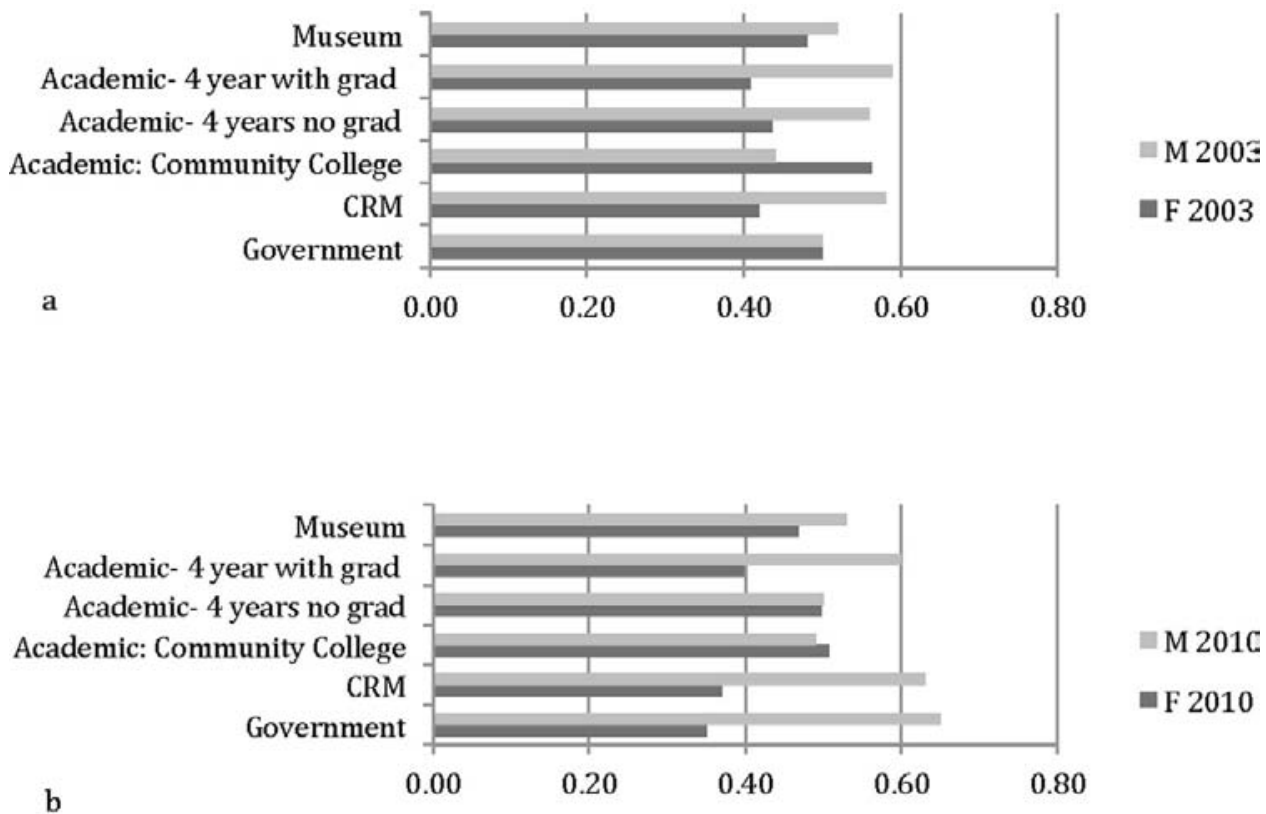

Figure 5. Percentages of archaeology job positions by sex based on 2003 and 2010 Society for American Archaeology (SAA) member surveys (data provided by SAA). CRM = cultural resource management.

A follow-up study that includes interviews with men would be helpful in showing relative degrees of service and advising for men and women.

Our data point to several different aspects of hidden labor for women that impact both their ability and their desire to seek major grants. Here "hidden labor" refers to the idea of additional social and emotional costs incurred in effectively pursuing a career but which go unnoticed or uncompensated (see, for example, Acker and Armenti 2004; Acker and Feuerverger 1996; Bellas 1999; Benschop and Brouns 2003; Green 2015; Howe-Walsh et al. 2016; Ogbonna and Harris 2004; Probert 2005).

Workplace inequalities are largely contingent on the setting in which women work. Women who have not applied for major grants, many of whom are at "teaching institutions," reported 


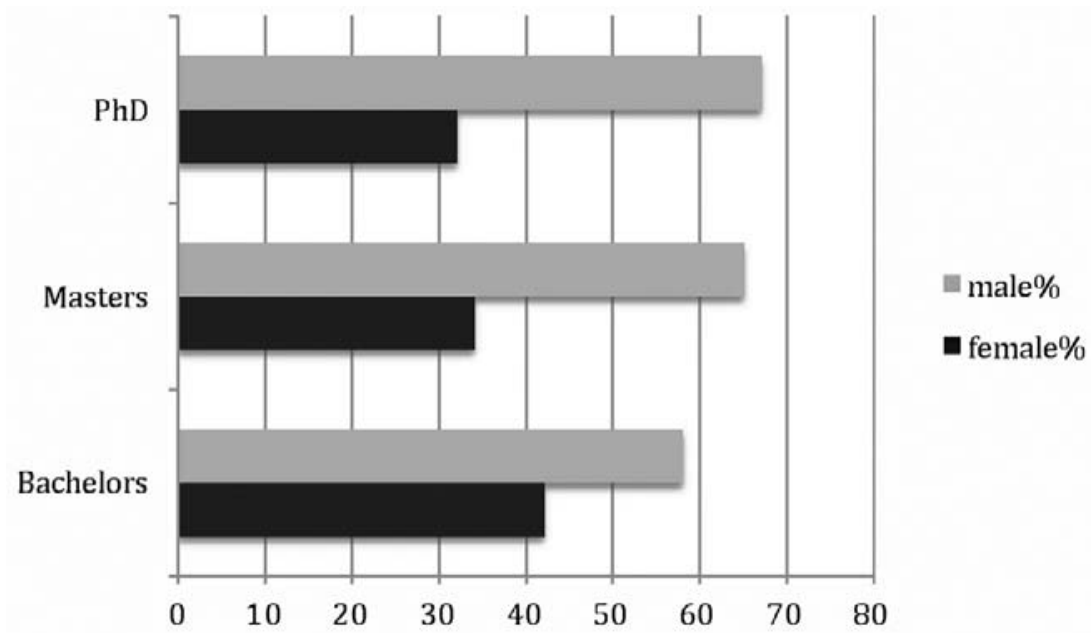

Figure 6. Percentage of archaeologists who are faculty in different types of degree-granting institutions, 2011 (data provided by the American Anthropological Association).

high levels of teaching and service as a contributing factor shaping their career. Of the women interviewed, only two of those who had applied for a major grant came from an institution with a teaching load of $3 / 3$, and one reported a teaching load of $4 / 4$. Those at nonresearch institutions more frequently reported being in small departments, combined departments (e.g., Anthropology/Sociology), or interdisciplinary programs where faculty taught a wider variety of courses further from their areas of expertise. This constitutes a kind of hidden work in that the differences in teaching obligations between the $2 / 2$ load of a "research" institution and the $3 / 3$ or 4/4 load of a "teaching" institution are not merely in the number of contact hours and the number of students in a semester but also in the breadth of courses and the frequent rotation of courses, which distracts women at such "teaching" institutions from a research focus.

Service is harder to quantify than teaching loads and numbers of preparations, but both applicants and nonapplicants cited high service loads as a factor shaping their career. Nonapplicant women, however, cited service twice as frequently as those who had made grant applications. This is consistent with external data showing that academic women in general take on larger or more demanding service roles earlier in their careers, including directing undergraduate programs and chairing departments, often at the cost of delaying or stagnating their pursuit of things such as research that lead to promotion to full professor (Olsen, Maple, and Stage 1995; Park 1996). But, once again, we were not able to compare women's loads with men's.

\section{Because archaeology is (or was) perceived as more field-based than other subfields of anthropology, and because family responsibilities keep women from doing extensive fieldwork (particularly overseas), fewer women apply for NSF grants unless they are applying for fieldwork.}

The third hypothesis has three components. One is whether women do less fieldwork than men, especially as compared with other subdisciplines in anthropology. The data from NGS are especially useful here since it only funds fieldwork. As the data from this program show, US-based men apply at rates almost twice as high as USbased women, paralleling the NSF data and the demographic data for academic employment. The NSF data also show that more applications are for fieldwork than for laboratory work.

A second component relates to family responsibilities; almost every woman we interviewed discussed conflicts between their family responsibilities and scheduling fieldwork. Rather than staying out of the field altogether, however, many discussed how they did fieldwork through a 
combination of supportive partners and creative childcare.

The third component is the perception that NSF only funds projects with a fieldwork component. Several interviewees said that they thought NSF only funded fieldwork projectseven though this is not true. It may be that some women's perceptions of what agencies will fund are affecting application numbers, but this may also be true for men.

In general, women's perceptions about NSF Archaeology Program grants can be broken down into four general categories: subject matter, methodology, line items, and affiliation of the principal investigator. Subject matter and methodology include whether NSF funds work in historical archaeology, biological archaeology, or feminist archaeology and whether NSF preferentially favors international work over domestic projects and survey over excavation. Line items include questions about summer salary or childcare. Finally, women working outside academia asked, "Will NSF fund me?" Does their affiliation matter? Can women who work in nontenure-track or adjunct faculty positions or in CRM apply?

Before they apply to NSF, some women need to feel that they are doing important research, are directing high-visibility projects, and are capable of convincing peer reviewers that their grant request is "the most perfect." Some commented that they did not apply because their work was "not big-picture enough or long-term enough"; others were concerned that they would take on something too big for their abilities, particularly given the timetable associated with a grant.

\section{Women tend to conduct smaller projects and therefore go to WG, NGS, and other funding sources for smaller amounts of money.}

NSF data show that the dollar amounts of successful grants are not statistically different between men and women. However, the data from WG and NGS suggest that women apply at higher rates to both of these foundations than to NSF. For WG, it appears that an earlier disparity that corresponded with the 2009 recession has somewhat resolved itself, and for NGS, women have recently shown dramatic success in funding. Both of these organizations have caps on funding levels that are much lower than NSF averages, and their applications are much shorter in length. However, we note that there are overall fewer archaeological applicants to these programs.

Many of the women we interviewed demonstrated a practice that we term scaffoldingputting together a package of smaller grants to initiate a project, perhaps with the goal of adding a larger grant to this framework later. Scaffolding may include stretching out start-up packages and other internal sources of funding, obtaining funding from federal and state heritage programs (especially for North Americanists), and receiving grants from foundations such as Leakey and Alphawood. NEH is the only agency where something approaching parity is demonstrated and which shows a steady increase in successful applications by women over the past two decades. This pattern for NEH may be because the grants covered in our analysis included fellowships and fellowships are focused on an individual scholar's project. However, three of our interviewees had applied to NEH for collaborative research projects, two of whom were successful and as a result had not applied to NSF. In the case of these NEH collaborative grants, they were not smaller but on par with what NSF would have funded. Together these data suggest that it is not project size that is responsible for women's lower submission rates to NSF but other factors including creative scaffolding. A number of women noted that the return on investment for NSF grant preparation was not always worthwhile.

Our interviews illuminate how women fund their work through strategic planning and scaffolding. It was also clear from our interviews that women were strategically thinking about when to apply to NSF within their own career and project trajectories. Several women said that they had stretched out their start-up funds and so did not apply for funding from NSF. In one case, it was because the researcher was asked to do "above and beyond" service, delaying the setup of her lab, and thus received permission to extend the time limit for spending start-up funds. In the future, she expected to apply for smaller grants and to use contract funds. There also seems to be a general recognition that startup funds are "beefier"; universities are putting 
up more money as part of their recruitment packages. One woman stated that at her $\mathrm{PhD}$ granting public university, you were expected to bring in grants equivalent to your start-up package, even though her anthropology program was MA-granting only.

Besides start-up funds, many women talked about how they had access to a variety of internal and external sources that allowed them to conduct pilot projects. One woman spoke about how as an administrator she did not take the extra stipend that came with the position but put it into a research account. Others mentioned several campus-wide grant opportunities for junior faculty that allowed them to conduct fieldwork. Still others explicitly mentioned how they first applied or planned on applying to WG and NGS as a way of getting into the field. For those who work in the United States, several also mentioned government-sponsored research support such as from the National Park Service, the Bureau of Land Management, and state organizations. Again, we do not know whether women are relying on these sources more than men, because our sample was focused only on women. Nonetheless, we see these alternatives to NSF as ways that women scaffold and build their grantsmanship, at the same time that they may delay applications to NSF.

\section{Women are going to other funding sources} within NSF, many of which are larger than Archaeology Program grants, therefore lowering the numbers for the Archaeology Program itself.

As NSF Archaeology continues with the same level of funding - or even less, given inflationthere is no question that all applicants are looking to other funding sources within NSF. We do not know whether women are doing this at a significantly higher rate than men, but several women mentioned that they had applied to alternative programs in NSF instead of NSF Archaeology, including large-scale research, training, and laboratory instrumentation grants. However, only one woman mentioned applying (albeit unsuccessfully) to Archaeometry, which remains heavily dominated by male PIs.

Many of these other NSF programs provide more funding but at different success rates. For example, NSF Polar Programs was mentioned by a few women working in applicable areas because it has higher success rates and more funding than NSF Archaeology. Similarly, during the period that shows a decline in women's submissions to NSF Archaeology, several senior women held research grants from NSF crossdirectorate programs with lower funding rates but with higher average funding levels. One woman also mentioned that she had (successfully) applied to NEH rather than NSF because of the nature of the questions that she was asking. As our data show, women have been increasingly successful at obtaining NEH grants that fund their field- and laboratory work.

\section{Women may not perceive their research as suitable for NSF; consequently, more women apply to other agencies such as NEH.}

From statements made by many interviewees, men appear more likely to apply and see what happens, while women told us that they believed that their proposals must be well honed (one used the word perfect) before applying. In a few cases, women's perceptions of NSF may not match the reality of what the agency will consider and fund, which suggests that continued outreach on the part of NSF program officers is important.

Because of the time involved in preparing a grant application, perceptions about the researcher's "fit" with the program affect whether or not she will make the effort to apply, as well as when and how she responds to the review process. For some, getting grants is simply "part of the job," but for others it is a measure of the importance of research, and NSF is seen as "the best," the "most competitive," and the "major funder." The amount of grant money potentially available makes putting together the grant application worth the effort, as it can fund long field seasons in international settings. Those who have participated in others' grants may question whether they can be competitive as the sole PI or put together a team.

When asked whether she had applied to NSF Archaeology in the last 10 years, 36\% (13) of interviewees said no. A total of $17 \%$ (6) interviewed had applied for a grant, did not get it, had reapplied, and eventually were awarded funding. Most interviewees indicated that if they were not 
awarded a grant after three tries, it was time to "move on." One woman had always applied as a co-PI because her work was primarily lab-based, and another tended to apply as a collaborator since she did not hold an academic position.

\section{Women's reactions to negative reviews are} different from men's and have resulted in their feeling discouraged from resubmission. If true, this tendency may be compounded by the current trend for proposals to not be funded during the first round within NSF Archaeology.

We do not have the data to compare the reactions of women and men to negative reviews, but our interviews suggest that negative reviews do have some effect on reapplications by some women. In at least two cases, interviewees reported that reviews were harsh enough to effect delays in reapplication and, in one case, the decision not to reapply. Such a result suggests that women's confidence was affected by negative critiques, but as with submissions to archaeology journals (Bardolph 2014:535-536), we do not have the data to assess the degree to which negative reviews affect resubmissions in a gendered way. Research on women in science and other fields shows evidence of a "confidence gap" (Kay and Shipman 2014). While some of this research is spurious, especially when citing biological factors (see Bleidorn et al. 2016), it is clear that social factors affecting women's confidence have an impact on their participation in science more generally. However, we also learned that women often make strategic decisions about NSF - they have limited time and are more likely to go to granting agencies with a higher rate of success than go back to NSF multiple times. In addition, other funding organizations have more user-friendly (i.e., shorter) application forms that require less time investment.

As a whole, interviewees appeared pragmatic in handling negative feedback from peer reviewers of both grants and publications (we did not distinguish in our question). Comments are triaged into three main categories:

1. Constructive and actionable, whether tough or not;

2. Irrelevant, wrong, silly, or political; and
3. Negative, brutal, discouraging, and demoralizing.

While negative criticism is a barrier that can prevent resubmission, it can be moderated by who provides the criticism: grant officers and editors carry more weight than peer reviewers.

Women are also strategic as they evaluate whether to persist with an unsuccessful application. On the one hand, resubmission was considered something that one does because "you always need the money." On the other hand, some women were discouraged after their initial submissions and did not reapply. The reasons for not resubmitting were varied, but one interviewee mentioned that although she received one very positive review, it seemed a slow, uphill battle to refine the proposal without help and it would have taken away from her teaching. Another interviewee mentioned the lack of support for grant preparation and the amount of time and effort required just to get it through her university system. Four women each mentioned how there seemed to be one panelist who kept her proposal from being funded and that it just was not worth the time investment until that person rotated off the panel. Several women also mentioned external reviewers' comments that kept them from resubmitting: "Hardest were ones that did not seem to see the project in the right light- 'It's risky, so let them do a few seasons of unfunded work and see what they find before they come back."” Another woman mentioned receiving advice from different reviewers on the same proposal that was diametrically opposed and so felt confused about what to take to heart and what to let go. And finally, one woman mentioned that there was a clear conflict of interest with one reviewer over perspective and methods that she knew she could not overcome, so she instead used field school funding for her project rather than reapply.

In general, when women have reached the point of submitting their grants and publications, they intend success. Resubmission is a recognized part of the process, and most setbacks are temporary.

However, although women may be pragmatic and strategic in general, this was not the case in their perception of program officers. Program 
officers are the best resource for reliable information about a granting program. While a few women specifically noted that they had received positive feedback from program officers, most women did not mention conversations with these officers concerning application, reapplication, and mentorship. One interviewee remarked that her university had brought in an agency program officer and a man in the audience said that he would call the program officer at the agency to ask whether it would fund a project he was considering. Women in the room were surprised and commented that women tend not to call male program officers and, more importantly, women see calling the office as asking for special attention or favors. Men in the audience were surprised at this response since this is the program officer's job.

\section{Women work more on their own than men in archaeology, and this may affect the frequency of grant submissions.}

NSF data indicate that women do not collaborate as much as men: $50 \%$ of men have co-PIs (of either sex), while only $16 \%$ of women do. Of course, women collaborate, including in many cases with their partners, but the relatively lower rate in NSF proposals is concerning.

Collaboration is an important variable in the production of science resulting in, among other benefits, high publication rates in many fields (e.g., Lee and Bozeman 2005). Of course, collaboration can detract from research success if managing the collaborators is too timeconsuming or if the researchers are incompatible or unproductive. But as Lee and Bozeman point out, the growing trend toward interdisciplinary or even transdisciplinary research (Mode 2 research in Gibbons et al. 1994) often requires research teams. We expect that this will be more important in the future, so low collaboration rates by women are therefore concerning. The National Research Council (2015) explicitly recognizes the importance of collaborative teams and offers important models for successful projects.

Collaboration may be particularly salient in the persistence and success of "borderline" applicants-those with higher teaching loads who express interest and a desire to continue to engage in high-level research. One interviewee from an M.A.-granting program, for example, reported that she had collaborated with a close colleague outside of her department-someone she had known since graduate school-who encouraged her to persist in pursuing a particular project, making multiple applications until they were successful. Two others (one from an M.A.granting institution, the other from a B.A.-only program) had applied to NSF and abandoned the project because they felt that they lacked the open feedback (as opposed to anonymous reviews) they needed to successfully refine their applications. Perhaps not coincidentally, these subjects were also working as solo PIs.

The work to maintain mentoring and collaboration also impacts grant application for women in the peer-review process. On the one hand, those who had applied for grants maintained a neutral view of the peer-evaluation process overall; it could be rigorous, and sometimes "people say stupid things," but the process worked. Many reported the direct or indirect support of mentors and collaborators, people who affirmed the validity of a proposal and who then encouraged/collaborated on resubmission. On the other hand, those who had not applied for major grants held an overall negative opinion of the peer-review process and suggested that slow and sometimes discouraging progress through the system for both grants and publications limited their ability or desire to submit major grant applications; discouraging reviews slowed revisions and resubmissions of publications, and having "too few" publications was cited as a reason not to apply for a highly competitive grant.

\section{The nature of archaeological field research includes a number of stresses, such as long field seasons, difficult living conditions, long-distance travel, the coordination of large crews, and close living quarters with colleagues. Such conditions limit women's ability to find appropriate childcare.}

Childcare and family responsibility concerns are of critical importance to women as they plan their research projects. As noted earlier, it takes a great deal of planning and strategizing for a woman to line everything up so that she can go into the field. We have learned that it is far more reliable for a number of women to put together smaller 
amounts of money to have greater certainty that their plans will work with their schedules.

Across the board, informants also identified work/life balance issues as a major factor in their research career. Two elements played the most critical role-childcare and spouses. First and most uniformly, those researchers with children cited them as a challenge to the research process in general. Where adequate arrangements could be made for children while conducting research, arranging for childcare was extra work for which informants reported taking primary responsibility. For others, combinations of financial costs, family expectations, ${ }^{4}$ and safety/health concerns for children were cited as contributing factors in postponing grant applications even among those who had gone on to apply. Single mothers in the sample found the cost of childcare a particular deterrent to applying for those grants that do not allow budgeting for such costs.

In terms of spouses, our data reveal two patterns. First, and perhaps not surprisingly, archaeologists tend to marry other archaeologists; the most common occupation given for a spouse was "archaeologist," with related fields such as cultural anthropology and history in distant second and third places. Applicants and nonapplicants varied, however, in that among applicants, twothirds of those who were married reported being married to an archaeologist, while only two-fifths of the nonapplicants reported having married an archaeologist. Similarly, spouses were much more likely to hold a $\mathrm{PhD}$ among NSF applicants (about two-thirds) than among nonapplicants, only half of whose spouses held a $\mathrm{PhD}$.

Second, about two-thirds of the grant applicants reported that their partner was helpful, while only a third of nonapplicants reported helpful partners. Two unsuccessful applicants also reported partners being "not particularly helpful." What constitutes "helpful" was left open-ended. Subjects with helpful partners most often described mutual relationships in which subject and partner acted as sounding boards for each other's ideas, collaborated on grants and projects, helped with revisions and resubmissions of proposals and publications, and supported practical solutions to childcare during field research. Women with a partner not described as helpful sometimes saw their partner as emotionally or financially supportive but not offering any direct support of career goals. In a few cases, however, subjects attributed limits on their research as compromises with unhelpful partners.

\section{Conclusions and Recommendations}

In archaeology today, more than half of all $\mathrm{PhD}$ degrees are awarded to women. Yet, within academia, and even in other professional archaeology positions, women are not proportionately placed in jobs. Within academia, women tend to appear in those positions with more teaching and no graduate students. The overall increase in women at the entry assistant professor level is a positive sign, but only if these individuals can maintain productivity and obtain promotions and tenure. It is not clear whether the lower proportion of women in research-intensive institutions is due to (1) women not applying for these jobs because of concern about the demands of the positions, (2) men being given preference over women in hiring, (3) men currently in these positions retiring later than anticipated, or (4) fewer of these positions being filled.

Women are not applying for NSF and other grants at the same rate as men, and this may be a function of their smaller numbers in research institutions and greater presence in teachingintensive colleges and universities. However, success in grantsmanship often depends on reapplying for grants, and women do not necessarily reapply as often. For many women, the time spent in writing and rewriting grant proposals is seen as a poor investment when they can scaffold smaller amounts of grant and foundation funds for field projects in order to get the work done and maintain better scheduling of work. Since women generally juggle other responsibilities in addition to their careers, planning for a dependable field season often takes priority over being awarded a prestigious grant. Men may be more likely to focus on the prestigious grant, but this remains to be investigated.

Of the 36 women interviewed, only one stated that she did not see herself as successful in any way. We divided the reasons that women provided as the basis for their success into one or more of four categories: (1) personal 
qualities, (2) training and education, (3) family qualities, and (4) institutional qualities. Under the general category of personal qualities, the most commonly stated reasons for success were patience and persistence. Under training and education, graduate training and good role models were seen as most influential. Family support, reflected in many forms, was critical to many, and institutions were most helpful when they provided supportive colleagues, departments, and institutional structures, as well as helpful agency program officers.

A somewhat surprising finding of the interviews is the fact that a majority of women listed their graduate training and good role models as keys to their success, regardless of the age of the woman or the length of time since she had attended graduate school. This suggests that a focus on strong, consistent, and supportive graduate training in designing projects and applying for funding, as well as other professional activities, remains critical to future success.

Several important findings from this study should be considered and acted upon by granting agencies, colleges and universities, and professional associations such as the SAA. Women may operate on a different schedule for career development, they may be more pragmatic than aspirational in their motivations, they may require different kinds of funding, and they need mentoring and clear advice on research development and funding, as well as supportive partners and families.

In an article focused on women's underrepresentation in science fields, Ceci and Williams (2011) highlight several issues and recommendations that we have found also apply to archaeology. First, they found no gender bias in awarding grants; men's and women's grants were approved at the same rate. Ceci and Williams argue that women's underrepresentation is the result of "career preferences and fertility/lifestyle choices, both free and constrained" (2011:3161). For archaeology and other disciplines, we are concerned with the choices that are constrained, and there is evidence that the fieldwork nature of archaeology places another burden on developing successful projects. We would also suggest that these "choices" are not always real choices but pragmatic ways in which women have found to adapt, not always successfully. Ceci and Williams (2011:3161-3162) suggest that universities explore options for offering women part-time tenure-track jobs (with concomitantly longer periods of time in which to amass a tenure portfolio), posts that could eventually segue to full-time once the women were ready. However, implementing such flexible options will require a lot of work and resources as well as evaluation of the impact of such a structure on graduate students. Finally, we agree with Ceci and Williams that

the linear career path of the modal male scientist of the past may not be the only route to success, and departments and universities should be encouraged and funded to experiment with alternate lifecourse options. A partnership between the academy and federal funding agencies could be instrumental in researching such alternatives [2011:3162].

Other creative suggestions provided by women we interviewed include the need for childcare-several asked why granting agencies could not approve such costs as part of a grant. Subsequent to this study, NGS decided to allow childcare costs as an allowed grant expense. ${ }^{5}$ Others noted that a more extended timeline for awarded grants could be helpful in their successful completion of a project.

The topic of mentoring came up as an important issue in a number of discussions with women. All graduate students need training on research project development, grant writing, grant administration, and other professional issues, but women especially need this training since they often do not receive the kind of informal training and mentoring that men have traditionally had. Women who received such training in graduate school raised the importance of such preparation again and again. Training should include attention to factors such as collaboration in grants and publications and how to manage research teams, the importance of scaffolding to obtain funding for research, understanding what different agencies/programs will and will not fund, promoting confidence and how to address negative reviews, and planning for the inevitability of resubmissions, among other topics. 
Granting agencies, as well as publication editors, should consider removing reviewers who provide ad hominem attacks in their reviews. These kinds of reviews are not productive for anyone. If there is a useful comment or critique in the review, this comment should be sent to the author, but with a note that indicates that only that one section was useful and that the decision was not based on the entire review. In addition, it is important for agencies and editors to be alert to potential gender biases in reviews.

It would be especially powerful for granting agencies, professional organizations (such as the SAA), and universities to create a partnership to train and mentor women and research alternative career paths. The traditional linear path may not be the only possible route to success. Women need to learn practical knowledge about developing research projects, as well as simple information such as knowing that approaching grant agency officers is standard practice that can significantly and positively affect their grant proposals.

\section{Recommendations for Funding Agencies}

1. Make clear what topics or areas of study you fund and do not fund. For example, many people interviewed did not think that NSF funds historical archaeology and thought that WG and NGS do not fund US-based research.

2. Make clear who can apply for funding and who cannot.

3. NGS has recently changed its grants program and now includes childcare as an allowable expense. Other agencies and organizations should also consider such changes.

4. Post samples of full proposals (as NEH does).

5. Highlight what other (e.g., NSF) programs are appropriate for archaeological applications.

6. Invite a group of senior scholars and program officers from various agencies and foundations to a meeting to develop a checklist for potential archaeology applicants: What kind of travel is/is not funded? How does one calculate mileage and use the federal funding guidelines for per diems? Is childcare or hiring on-site cooks funded, and how does one put such things into a budget? Even at major research universities, the staff in the Sponsored Projects Office frequently do not "get" what archaeological research projects involve, so they are often of little help in outlining kinds of expenses and how to craft budgets. This meeting would not provide answers, since these vary by agency and foundation, but would develop the important questions.

\section{Recommendations for Applicants}

1. Always contact the program officer and ask lots of questions.

2. Look at past successful grant titles and abstracts to identify the kinds of research being funded.

3. Ask for sample proposals in your area of interest.

4. Keep revising and resubmitting proposals if you receive some positive reviews. Some applicants submit proposals three or four times before receiving awards.

5. Think about how to put together research teams. More research is being funded and conducted with larger research groups. The lone researcher model is becoming less viable for many kinds of archaeological projects.

\section{Recommendations for SAA}

1. Encourage program officers to conduct inperson and online training through the SAA. Sessions should be tailored for senior proposal writers, not just students interested in dissertation funding.

2. Support the scholar/agency meeting to create checklists, as in recommendation 6 for funding agencies.

3. Initiate data collection on adjunct and parttime faculty, as well as non-tenure-track/ limited-term/short-contract/nonpermanent faculty.

4. Incorporate specific questions for the Discovering the Archaeologists of the Americas survey and other future surveys.

5. Support and supply mentoring on a variety of topics related to developing projects and collaborations and applying for research grants.

\section{Summary}

Our research supports previous studies that have investigated gender disparities across a number of domains, including publishing and hiring. 
While the number of women in the profession has increased, it is clear that the variables we discuss have not changed as much as many hoped. The factors that contribute to gender disparities should continue to be recognized and tracked. We encourage academic advisers, mentors, granting agencies, editors, and others to be mindful that gender disparities remain a factor in professional trajectories and to consider how their actions and decisions can create more equitable participation.

Acknowledgments. First, we want to thank the women who generously gave their time to be interviewed for this project; we are both thankful and impressed with your accomplishments. We likewise acknowledge the support and generous assistance of the Society for American Archaeology Executive Board, the National Science Foundation (BCS1449667), the Wenner-Gren Foundation for Anthropological Research, the National Geographic Society, the American Anthropological Association, and Doug Rocks-Macqueen. We also thank and acknowledge the input of the reviewers of this manuscript. They made great suggestions, which we tried to incorporate to the extent possible.

Data Availability Statement. In order to make the data collected and the results of this study as available as possible, we created a project website (http://saa-gender.anthropology. msu.edu) developed in collaboration with Matrix (Michigan State University Center for Digital Humanities and Social Sciences). A complete copy of the task force's report is available from the site, as well as copies of the forms we used, each of the hypotheses, and our analyses. Data summaries are included on the site. We have also made available a variety of published papers and reports that the task force used or referenced in writing this report. This website will be maintained for future reference and use.

Some of these publicly available data have been previously made available online by Doug Rocks-Macqueen on his website: https://dougsarchaeology.wordpress.com/ 2014/03/11/gender-inequalities-in-archaeology-plays-outin-nsf-funding/.

Each interviewer maintained detailed notes on each interview, and all identifiers were removed from the notes. Interviews were conducted by Goldstein, Mills, Herr, and Burkholder.

\section{References Cited}

Acker, Sandra, and Carmen Armenti

2004 Sleepless in Academia. Gender and Education 16:3-24.

Acker, Sandra, and Grace Feuerverger

1996 Doing Good and Feeling Bad: The Work of Women University Teachers. Cambridge Journal of Education 26:401-422.
Bardolph, Dana N.

2014 A Critical Evaluation of Recent Gendered Publishing Trends in American Archaeology. American Antiquity 79:522-540.

Bardolph, Dana N., and Amber M. VanDerwarker

2016 Sociopolitics in Southeastern Archaeology: The Role of Gender in Scholarly Authorship. Southeastern Archaeology 35:175-193.

Beaudry, Mary C.

1994 Women Historical Archaeologists: Who's Counting? In Equity Issues for Women in Archaeology, edited by Peggy Nelson, Sarah Nelson, and Alison Wylie, pp. 225-228. Archaeological Papers of the American Anthropological Association 5. American Anthropological Association, Washington, DC.

Beaudry, Mary C., and Jacquelyn White

1994 Cowgirls with the Blues? A Study of Women's Publication and the Citation of Women's Work in Historical Archaeology. In Women in Archaeology, edited by Cheryl Claassen, pp. 138-158. University of Pennsylvania Press, Philadelphia.

Bellas, Marcia L.

1999 Emotional Labor in Academia: The Case of Professors. Annals of the American Academy of Political and Social Science 561:96-110.

Benschop, Y., and M. Brouns

2003 Crumbling Ivory Towers: Academic Organizing and Its Gender Effects. Gender, Work and Organization 10:194-212.

Bleidorn, Wiebke, Ruben C. Arslan, Jaap J. A. Denissen, Peter J. Rentfrow, Jochen E. Gebauer, Jeff Potter, and Samuel D. Gosling

2016 Age and Gender Differences in Self-Esteem-A Cross-Cultural Window. Journal of Personality and Social Psychology 111:396-410.

Burkholder, Jo Ellen

2006 Doing It for Ourselves: Women and Participation in the SAA Annual Meetings. SAA Archaeological Record 6(2):27-31.

Ceci, Stephen J., and Wendy M. Williams

2011 Current Causes of Women's Underrepresentation in Science. Proceedings of the National Academy of Sciences 108:3157-3162.

Chester, Hilary, Nan A. Rothschild, and Diana diZerega Wall 1994 Women in Historical Archeology: The SHA Survey. In Equity Issues for Women in Archeology, edited by Peggy Nelson, Sarah Nelson, and Alison Wylie, pp. 213-218. Archeological Papers of the American Anthropological Association 5. American Anthropological Association, Washington, DC. DOI: 10.1525/ap3a.1994.5.1.213, accessed October 2, 2016.

Claassen, Cheryl, Michael O’Neal, Tamara Wilson, Elizabeth Arnold, and Brent Landsell

1999 Hearing and Reading Southeastern Archaeology: A Review of the Annual Meetings of SEAC from 1983 through 1995 and the Journal Southeastern Archaeology. Southeastern Archaeology 18:85-97.

Clauset, Aaron, Samuel Arbesman, and Daniel B. Larremore

2014 Systematic Inequality and Hierarchy in Faculty Hiring Networks. Science Advances 1: e1400005. DOI: 10.1126/sciadv.1400005, accessed October 2, 2016.

Finkel, Susan K., and Steven G. Olswang

1996 Child Rearing as a Career Impediment to Women Assistant Professors. Review of Higher Education 19:123-139. 
Fox, Mary F., and Carol Colatrella

2006 Participation, Performance, and Advancement of Women in Academic Science and Engineering: What Is at Issue and Why. Journal of Technology Transfer 31:377-386.

Gibbons, Michael, Camille Limoges, Helga Nowotny, Simon Schwartzman, Peter Scott, and Martin Trow

1994 The New Production of Knowledge: The Dynamics of Science and Research in Contemporary Societies. SAGE, Thousand Oaks, California.

Green, Myra

2015 Thanks for Listening. Chronicle of Higher Education, October 19. Electronic document, http: //chronicle.com/article/Thanks-for-Listening/233825, accessed October 2, 2016.

Howe-Walsh, Liza, Sarah Turnbull, Emmanouil Papavasileiou, and Nikos Bozionelos

2016 The Influence of Motherhood on STEM Women Academics' Perceptions of Organizational Support, Mentoring and Networking. Advancing Women in Leadership 36:54-63.

Hutson, Scott R.

1998 Institutional and Gender Effects on Academic Hiring Practices. SAA Bulletin 16(4):19-21.

2002 Gendered Citation Practices in American Antiquity and Other Archaeological Journals. American Antiquity 67:331-342.

Kay, Katty, and Claire Shipman

2014 The Confidence Gap. Atlantic, May. Electronic document, http://www.theatlantic.com/magazine/archive/ 2014/05/the-confidence-gap/359815/, accessed October 2, 2016.

Larivière, Vincent, Chaoqun Ni, Yves Gingras, Blaise Cronin, and Cassidy R. Sugimoto

2013 Bibliometrics: Global Gender Disparities in Science. Nature 504(7479):211-213.

Lee, Sooho, and Barry Bozeman

2005 The Impact of Research Collaboration on Scientific Productivity. Social Studies of Science 35:673-702.

Nelson, Margaret C., Sarah M. Nelson, and Alison Wylie (editors)

1994 Equity Issues for Women in Archeology. Archeological Papers of the American Anthropological Association, No. 5. American Anthropological Association, Washington, DC.

National Research Council

2015 Enhancing the Effectiveness of Team Science. National Academies Press, Washington, DC. DOI: 10.17226/19007, accessed October 2, 2016.

Ogbonna, Emmanuel, and Lloyd C. Harris

2004 Work Intensification and Emotional Labour among UK University Lecturers: An Exploratory Study. Organization Studies 25:1185-1203.

Olsen, Deborah, Sue A. Maple, and Frances K. Stage

1995 Women and Minority Faculty Job Satisfaction: Professional Role Interests, Professional Satisfactions, and Institutional Fit. Journal of Higher Education 66:267293.

Park, Shelley M.

1996 Research, Teaching, and Service: Why Shouldn't Women's Work Count? Journal of Higher Education $67: 46-84$

Probert, Belinda

2005 "I Just Couldn't Fit It In": Gender and Unequal Outcomes in Academic Careers. Gender, Work and Organization 12:50-72.
Rautman, Alison E.

2012 Who Gets Published in American Antiquity? SAA Archaeological Record 12(2):25-26, 30.

Speakman, Robert J., Carla S. Hadden, Matthew H. Colvin, Justin Cramb, K. C. Jones, Travis W. Jones, Corbin L. Kling, Isabelle Lulewicz, Katharine G. Napora, Katherine L. Reinberger, Brandon T. Ritchison, Maria Jose Rivera-Araya, April K. Smith, and Victor D. Thompson

2017 Choosing a Path to the Ancient World in a Modern Market: The Reality of Faculty Jobs in Archaeology. American Antiquity. Electronic document, https://www. cambridge.org/core/journals/american-antiquity/ article/choosing-a-path-to-the-ancient-world-in-amodern-market-the-reality-of-faculty-jobs-inarchaeology/5060C3C3A4C2D6F7A2B8FA1 D420072B1, accessed January 10, 2018.

Stark, Barbara L., Katherine A. Spielmann, Brenda Shears, and Michael Ohnersorgen

1997 The Gender Effect on Editorial Boards and in Academia. SAA Bulletin 15(4):6-9.

Victor, Katherine, and Mary C. Beaudry

1992 Women's Participation in American Prehistoric and Historic Archaeology: A Comparative Look at the Journals American Antiquity and Historical Archaeology. In Exploring Gender through Archaeology, edited by Cheryl Claassen, pp. 11-22. Prehistory Press, Madison, Wisconsin.

West, Jevin D., Jennifer Jacquet, Molly M. King, Shelley J. Correll, and Carl T. Bergstrom

2013 The Role of Gender in Scholarly Authorship. PLoS ONE 8: e66212. DOI: 10.1371/journal.pone.0066212, accessed October 2, 2016.

Wolverton, Ann, Lisa Nagaoka, and Mimi Wolverton

2014 Breaking In: Women's Accounts of How Choices Shape STEM Careers. Stylus, Sterling, Virginia.

Yellen, John

1983 Women, Archaeology, and the National Science Foundation. In The Socio-politics of Archaeology, edited by Joan Gero, David M. Lacy, and Michael L. Blakey, pp. 59-65. Department of Anthropology Research Report No. 23. University of Massachusetts, Amherst.

1991 Women, Archaeology, and NSF: An Analysis of Fiscal Year 1989 Data. In The Archaeology of Gender, edited by Dale Wade and Noreen Willows, pp. 201210. University of Calgary Archaeological Association, Calgary, Alberta, Canada.

Zeder, Melinda A.

1997 The American Archaeologist: A Profile. Society for American Archaeology and AltaMira Press, Walnut Creek, California.

\section{Notes}

1. It may appear that we use the terms sex and gender interchangeably, and we do not mean to imply that they are. The task force name included the term gender disparities, so we have left the term gender when referring to the whole project. In addition, for most of our data, people indicated their gender.

2. Goldstein obtained Institutional Review Board approval (\# x14-682e) through Michigan State University before any interviews took place. All information shared during these interviews is treated as confidential, and names 
were removed from the data before the interviews were integrated into a larger database. The interviews included a set of standard questions, and respondents were encouraged to provide more detailed and extensive information in explaining their own situations.

3. The American Anthropological Association (AAA) generously provided data for 2008, 2009, 2010, and 2011 that form the basis of their AAA Guide to Departments of Anthropology. We used these data directly and did not use the actual printed or online Guides.

4. Family expectations here encompass a wide variety of issues including but not limited to how long family members thought it was acceptable for a parent to be away from a child, the willingness of a spouse or other family members to assist with childcare, and definitions of what constitutes "adequate" childcare.

5. As part of the recent transformation of the NGS grant program, it has set a target to reach gender parity in grants awarded and has included childcare in allowable expenses in an attempt to reach that target.

Submitted July 30, 2017; Revised October 18, 2017; Accepted October 21, 2017 